\title{
Desain Ruang Terbuka Hijau Jenis Taman Warga di dengan Pendekatan "Green Architecture" di Bantaran Sungai Winongo
}

\author{
Arina Amaliyah Hasanah', Hapsari Wahyuningsih'2 \\ ${ }_{1}$ Program Studi Arsitektur, Fakultas Sains \& Tekhnologi Universitas Aisyiyah Yogyakarta \\ 2 Program Studi Arsitektur, Fakultas Sains \& Tekhnologi Universitas Aisyiyah Yogyakarta \\ Email: arinahasanahh@gmail.com
}

\begin{abstract}
ABSTRAK
Daerah Aliran Sungai (DAS) sungai Winongo memiliki aliran cukup besar, sehinga sering menimbulkan banjir di bantaran Sungai Winongo. Hal ini diperparah dengan pemukiman penduduk dan adanya Tempat Pembuangan Akhir (TPA) dibangun di bantaran sungai, Yang menyebabkan fungsi tata guna lahan berubah dan berdampak pada meluapnya air sungai karena penampang sungai yang semakin sempit, sehingga tidak bisa menampung air secara optimal. Oleh karena itu, warga bersama beberapa lembaga lingkungan, untuk memenuhi jumlah presentase persyaratan RTH publik yang saat ini hanya memiliki 8,34\%, dari target UU Penataan Ruang di Yogyakarta yaitu 20\%, TPA Jatimulyo tersebut di ubah fungsinya menjadi Ruang terbuka hijau (RTH). Perencanaan Ruang terbuka hijau (RTH menggunakan konsep Green Architecture serta menggunakan standar yang tertera di UU Penataan Ruang. Konsep ini berusaha meminimalkan pengaruh buruk terhadap lingkungan alam maupun manusia dan menghasilkan desain atau tempat hidup yang lebih baik dan sehat, yang dilakukan dengan cara memanfaatkan sumber energi dan sumber daya alam secara efisien dan optimal serta mempunyai kualitas lingkungan dan menciptakan kehidupan yang lebih baik dan berkelanjutan dari segi sosial dan ekonomi. Serta mampu menumbuhkan kreatifitas, produktivitas warga kota serta dapat berekreasi secara aktif maupun pasif.
\end{abstract}

Kata Kunci: Green Architecture, Ruang terbuka hijau (RTH), Taman Warga Article history:: Received 2020-01-09; Revised 2020-02-22; Accepted 2020-06-2

\section{PENDAHULUAN}

Daerah Istimewa Yogyakarta dengan luas wilayah Daerah Istimewa yang memiliki luas $32,5 \mathrm{~km}^{2}$ ini terdiri atas satu kotamadya, dan empat kabupaten, yang terbagi lagi menjadi 78 kecamatan, dan 438 desa/kelurahan. Serta memiliki kepadatan penduduk sebesar 1.084 jiwa per $\mathrm{km}^{2}$. Dengan jumlah tersebut tidak di pungkiri bahwa alih fungsi lahan meningkat dari tahun ketahun untuk memenuhi kebutuhan penduduk dan aktivitas sosial ekonomi yang akhirnya mempengaruhi ketersediaan lahan dan berdampak pada keberadaan ruang terbuka hijau (RTH). sehingga Ruang Terbuka Hijau (RTH) yang ada di Yogyakarta pun makin berkurang.

Ruang terbuka hijau (RTH) diatur secara ketat dalam UU No. 26 Tahun 2007 tentang Penataan Ruang. Sebanyak 30\% dari luas total kota harus digunakan sebagai ruang terbuka hijau yaitu 20\% sebagai RTH publik dan

Desain Ruang Terbuka Hijau Jenis Taman Warga di dengan Pendekatan "Green Architecture" di Bantaran Sungai Winongo 
10\% RTH sebagai pribadi. Ruang terbuka hijau (RTH) di Yogyakarta pada tahun 2019, dengan total keseluruhan $17,82 \%$ yang terdiri dari area publik $8,34 \%$, yang masih jauh dari angka presentase persyaratan yaitu $20 \%$ seperti yang tertera di UU No. 26 Tahun 2007 tentang Penataan Ruang. sedangkan area privat yang di Yogyakarta yaitu 9,48\%. Angka tersebut sudah mendekati presentase persyaratan yang ada di UU, yaitu $10 \%$ untuk RTH private.

Daerah Aliran Sungai (DAS) sungai Winongo memiliki panjang sungai $43,75 \mathrm{~km}$ dengan luas daerah aliran sungai $88,12 \mathrm{~km} 2$. Secara garis besar Kota Yogyakarta merupakan dataran rendah dimana kontur dari barat ke timur relatif datar sedangkan dari utara ke selatan memiliki kemiringan \pm 1 derajat. Sehingga terdapat 3 (tiga) sungai yang melintas Kota Yogyakarta, yaitu Sungai Gajah Wong di Sebelah Timur, Sungai Code di Tengah Kota Yogyakarta, dan Sungai Winongo di Sebelah Barat. Pada saat musim hujan, Sungai Winongo memiliki aliran yang cukup besar dan sering menimbulkan banjir yang menggenangi daerah bantaran Sungai Winongo. Hal ini diperparah dengan banyaknya pemukiman penduduk yang dibangun pada bantaran sungai dan adanya Tempat Pembuangan Akhir (TPA) di area sungai Winongo khusus nya TPA Jatimulyo . Hal ini menyebabkan fungsi tata guna lahan berubah dan berdampak pada meluapnya air sungai karena penampang sungai yang semakin sempit tidak bisa menampung air secara optimal. Oleh karena itu warga bersama Forum Komunikasi Winongo Asri (FKWA) bekerja sama dengan Wahana Lingkungan Hidup Indonesia (WALHI) menutup TPA tersebut. Dengan dukungan Dinas Lingkungan Hidup (DLH) dan sesuai dengan keinginan warga, TPA Jatimulyo tersebut berubah fungsi menjadi Ruang terbuka hijau (RTH).

Tujuan perancangan Ruang terbuka hijau (RTH) di area sungai Winongo adalah untuk mengetahui dan menerapkan perencanaan desain RTH dengan pendekatan "Green Architecture". Serta di harapakan dapat memenuhi presentase standar pembagian tata guna lahan yang sesuai dengan UU No. 26 Tahun 2007 tentang Penataan Ruang. Khusus nya RTH publik yang belum mencapai standar UU yaitu $20 \%$.

\section{TINJAUAN PUSTAKA}

\section{Green Architecture}

Green Architecture atau disebut juga arsitektur ekologis atau arsitektur ramah lingkungan adalah konsep arsitektur yang berusaha meminimalkan pengaruh buruk terhadap lingkungan alam maupun manusia dan menghasilkan desain atau tempat hidup yang lebih baik dan lebih sehat, yang dilakukan dengan cara memanfaatkan sumber energi dan sumber daya alam secara efisien dan optimal serta mempunyai kualitas lingkungan dan menciptakan kehidupan yang lebih baik dan berkelanjutan.

Green Architecture Arsitektur Hijau memiliki kriteria sebagai berikut :(London,Themes and Hudson, 1991) 
A. Bahan bangunan terbarukan (material alami), Material terbaik untuk arsitektur hijau adalah usahakan menggunakan bahan daur ulang atau bisa juga dengan menggunakan bahan terbarukan sehingga membutuhkan sedikit energi untuk diproduksi.

B. Respect for Site (Menanggapi keadaan tapak pada bangunan), Perencanaan mengacu pada interaksi antara bangunan dan tapaknya. Hal ini dimaksudkan keberadan bangunan baik dari segi konstruksi, bentuk dan pengoperasiannya tidak merusak lingkungan sekitar, dengan cara sebagai berikut:

- Mempertahankan kondisi tapak dengan membuat desain yang mengikuti bentuk tapak yang ada.

- Luas permukaan dasar bangunan yang kecil, yaitu pertimbangan mendesain bangunan secara vertikal.

- Menggunakan material lokal dan material yang tidak merusak lingkungan.

- Menyesuaikan dan dapat mendukung kebutuhan pengguna secara sosial maupun ekonomi.

C. Conserving Energy (Hemat Energi)

Arsitektur dapat menjadi media yang paling berpengaruh dengan implementasi arsitektur berkelanjutan, karena dampaknya secara langsung terhadap lahan. Konsep desain yang dapat meminimalkan penggunaan energi listrik, misalnya, dapat digolongkan sebagai konsep sustainable dalam energi, yang dapat diintegrasikan dengan konsep penggunaan sumber cahaya matahari secara maksimal untuk penerangan, penghawaan alami pemanasan air untuk kebutuhan domestik, dan lain sebagainya, seperti :

- Memanfaatkan sinar matahari untuk pencahayaan alami secara maksimal pada siang hari, untuk mengurangi penggunaan energi listrik

- Memanfaatkan penghawaan alami sebagai ganti pengkondisian udara buatan (air conditioner). Menggunakan ventilasi dan bukaan,penghawaan silang, dan cara-cara inovatif lainnya.

Ruang Terbuka Hijau (RTH)

Ruang terbuka (open spaces) merupakan ruang yang direncanakan karena kebutuhan akan tempat-tempat pertemuan dan aktivitas bersama di udara terbuka. Sebagai wadah (container) untuk kehidupan manusia, baik secara individu maupun berkelompok, serta wadah makhluk lainnya untuk hidup dan berkembang secara berkelanjutan. Menurut Permendagri Nomor 1 Tahun 2007, jenis Ruang Terbuka Hijau Kawasan Perkotaan diantaranya yaitu :

- Taman kota,

- Taman wisata alam,

- Taman rekreasi,

- Taman lingkungan perumahan dan permukiman,

Desain Ruang Terbuka Hijau Jenis Taman Warga di dengan Pendekatan "Green Architecture" di Bantaran Sungai Winongo 
- Lapangan dan taman pemakaman

A. Fungsi RTH adalah sebagai berikut:

- Fungsi utama (intrinsik) yaitu fungsi ekologis, yaitu seperti memberi jaminan pengadaan RTH menjadi bagian dari sistem sirkulasi udara (paru-paru kota); pengatur iklim mikro agar sistem sirkulasi udara dan air secara alami dapat berlangsung lancar; sebagai peneduh dan juga produsen oksigen.

- Fungsi tambahan (ekstrinsik) yaitu seperti Fungsi sosial, budaya, ekonomi dan estetika.

B. Manfaat Ruang Terbuka Hijau (RTH)

- Manfaat langsung (dalam pengertian cepat dan bersifat tangible), yaitu membentuk keindahan dan kenyamanan (teduh, segar, sejuk) dan mendapatkan bahanbahan untuk dijual (kayu, daun, bunga, buah);

- Manfaat tidak langsung (berjangka panjang dan bersifat intangible), yaitu pembersih udara yang sangat efektif, pemeliharaan akan kelangsungan persediaan air tanah, pelestarian fungsi lingkungan beserta segala isi flora dan fauna yang ada (konservasi hayati atau keanekaragaman hayati).

C. Penyediaan RTH Berdasarkan Jumlah Penduduk

Untuk menentukan luas RTH berdasarkan jumlah penduduk, dilakukan dengan mengalikan antara jumlah penduduk yang dilayani dengan standar luas RTH per kapita sesuai peraturan yang berlaku.

- 250 jiwa : Taman RT, di tengah lingkungan RT

- 2500 jiwa : Taman RW, di pusat kegiatan RW

- 30.000 jiwa : Taman Kelurahan, dikelompokan dengan sekolah/ pusat kelurahan

- 120.000 jiwa : Taman kecamatan, dikelompokan dengan sekolah/ pusat kecamatan

- 480.000 jiwa : Taman Kota di Pusat Kota, Hutan Kota (di dalam/kawasan pinggiran), dan Pemakaman (tersebar)

D. prosedur perencanaan RTH

- penyediaan RTH harus disesuaikan dengan peruntukan yang telah ditentukan dalam rencana tata ruang (RTRW Kota/RTR Kawasan Perkotaan/RDTR Kota/RTR Kawasan Strategis Kota/Rencana Induk RTH) yang ditetapkan oleh pemerintah daerah setempat;

- tahapan penyediaan dan pemanfaatan RTH publik meliputi: perencanaan, pengadaan lahan, perencanaan teknik, pelaksanaan pembangunan $\mathrm{RTH}$, pemanfaatan dan pemeliharaan.

- penyediaan dan pemanfaatan RTH privat yang dilaksanakan oleh masyarakattermasuk pengembang disesuaikan dengan ketentuan perijinan pembangunan;

Desain Ruang Terbuka Hijau Jenis Taman Warga di dengan Pendekatan "Green Architecture" di Bantaran Sungai Winongo 


\section{PROSES RANCANG DAN EKSPLORASI}

Dalam proses merancang Taman Warga selain memperhatikan pedoman dan peraturan dari kementrian pekerjaan umum (PU), juga memperhatikan serta menerapkan konsep "Green Architecture".

1. Analisis Site

Analisis yang di gunakan untuk Taman Warga menggunakan 3 jenis analisis. Yaitu dengan analisis lapangan, analisis SWOT dan analisis data.

A. Analisis lapangan

Konteks tapak

a. Lokasi tapak

KONTEKS TAPAK

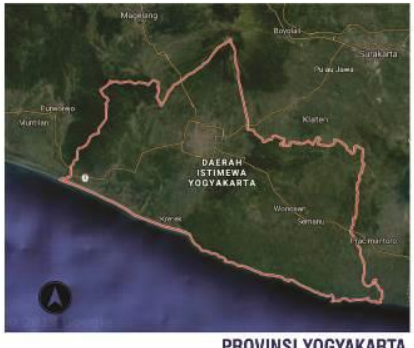

PROVINSI YOGYAKARTA

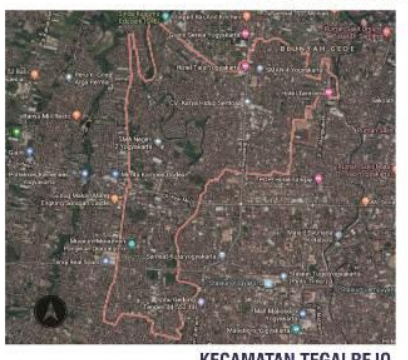

KECAMATAN TEGALREJO

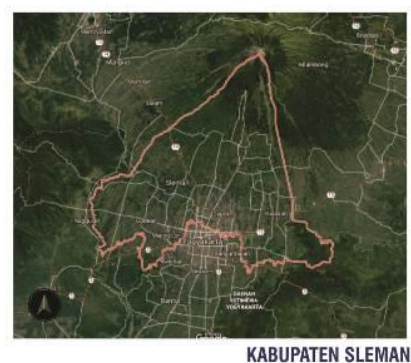

KABUPATEN SLEMAN

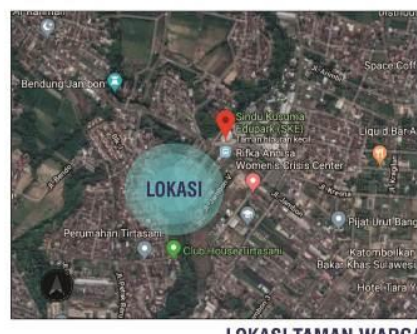

LOKASI TAMAN WARGA

Gambar.1 Konteks Tapak

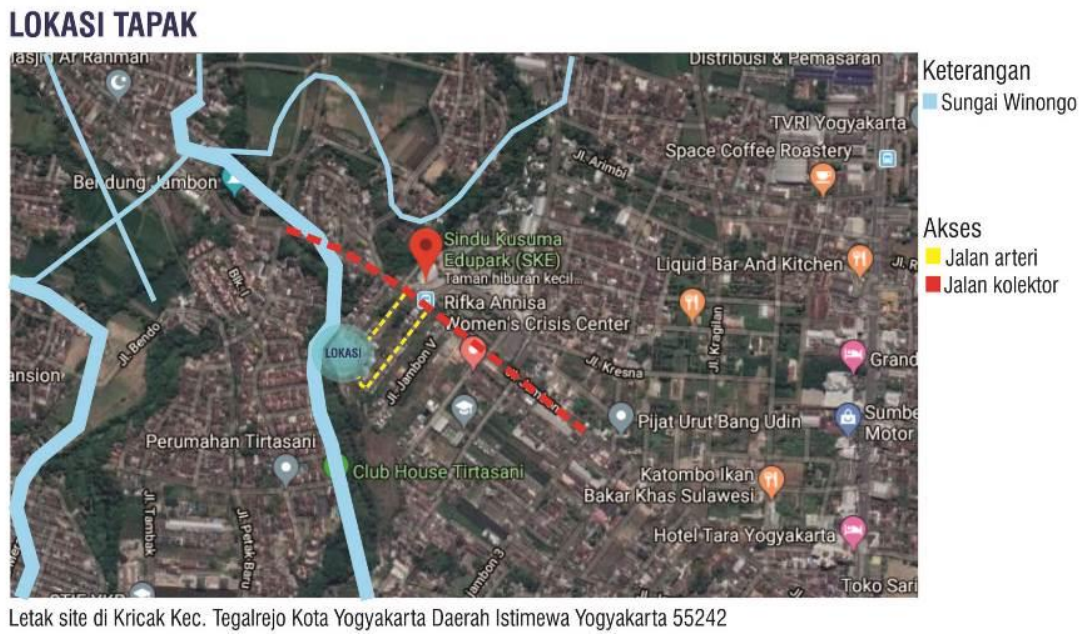

Gambar.2 Lokasi Tapak

Desain Ruang Terbuka Hijau Jenis Taman Warga di dengan Pendekatan "Green Architecture" di Bantaran Sungai Winongo 
Jarak antara jalan kolektor dengan site yang tidak terlalu jauh, sangat memungkinkan untuk wisatawan berkunjung. Akses jalan arteri yang selebar $3 \mathrm{~m}$, mudah di lalui oleh kendaraan roda dua dan empat

b. Kondisi eksisting

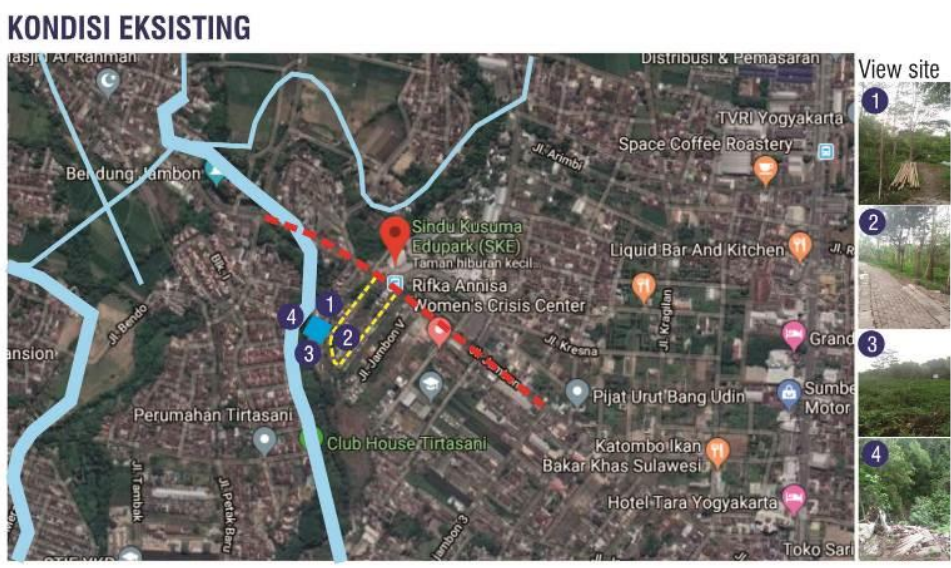

Gambar.3 Kondisi Eksisting

Lokasi site berada di bantaran sungai (4) sehingga sangat penting untuk membuat bataran sungai tersebut menjadi bermanfaat bagi sungai itu sendiri dan warga.

c. Sirkulasi eksisting

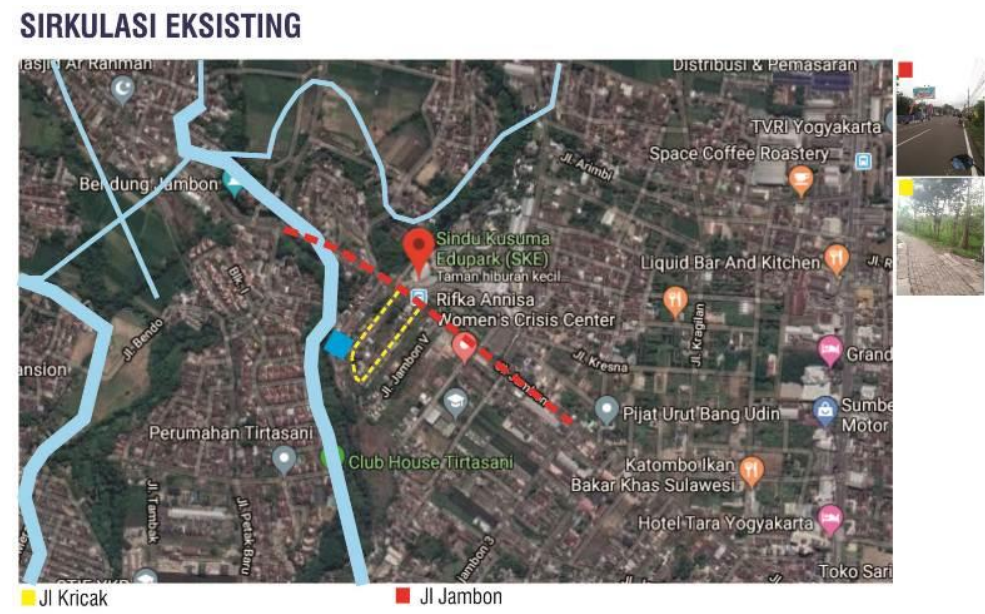

Gambar.4 Sirkulasi Eksisting

Site Taman Warga terletak di dekat bantaran sungai, juga pemukiman warga sehingga potensi untuk sering di kunjungi tinggi. Site Taman Warga tidak jauh dari jalan utama yaitu jl Jambon, sehingga potensi untuk di kunjungi dari wisatawan pun tinggi.

Desain Ruang Terbuka Hijau Jenis Taman Warga di dengan Pendekatan "Green Architecture" di Bantaran Sungai Winongo 
B. Analisis Kekurangan, Kelebihan, Peluang dan Ancaman

- Kekuatan (Strenght) : Daerah Kricak sudah di klaim (BAPEDA) menjadi kampung sayur karena pertanian yang sudah berkembang.

- Kekurangan (Weakness) : Fasilitas publik yang masih kurang dan belum optimalnya edukasi tentang hidroponik yang dapat membantu menambah kualitas petanian di Kricak

- Peluang (Opportunity) : Area site Taman Warga terletak di wilayah bantaran sungai. Klaim BAPEDA bahwa area tersebut adalah kampung sayur. Pemanfaatan lahan $400 \mathrm{~m}^{2}$ di RT 61 sudah di klaim DLH sebagai daerah hijau.

- Ancaman (Threat) : Banjir yang sering terjadi di bantaran sungai Winogo

C. Analisis data

Analisis data di ambil dari hasil notulensi pertemuan antara Forum Komunikasi Winongo Asri (FKWA), (Wahana Lingkungan Hidup Indonesia) WALHI dan warga yang hasilnya adalah :

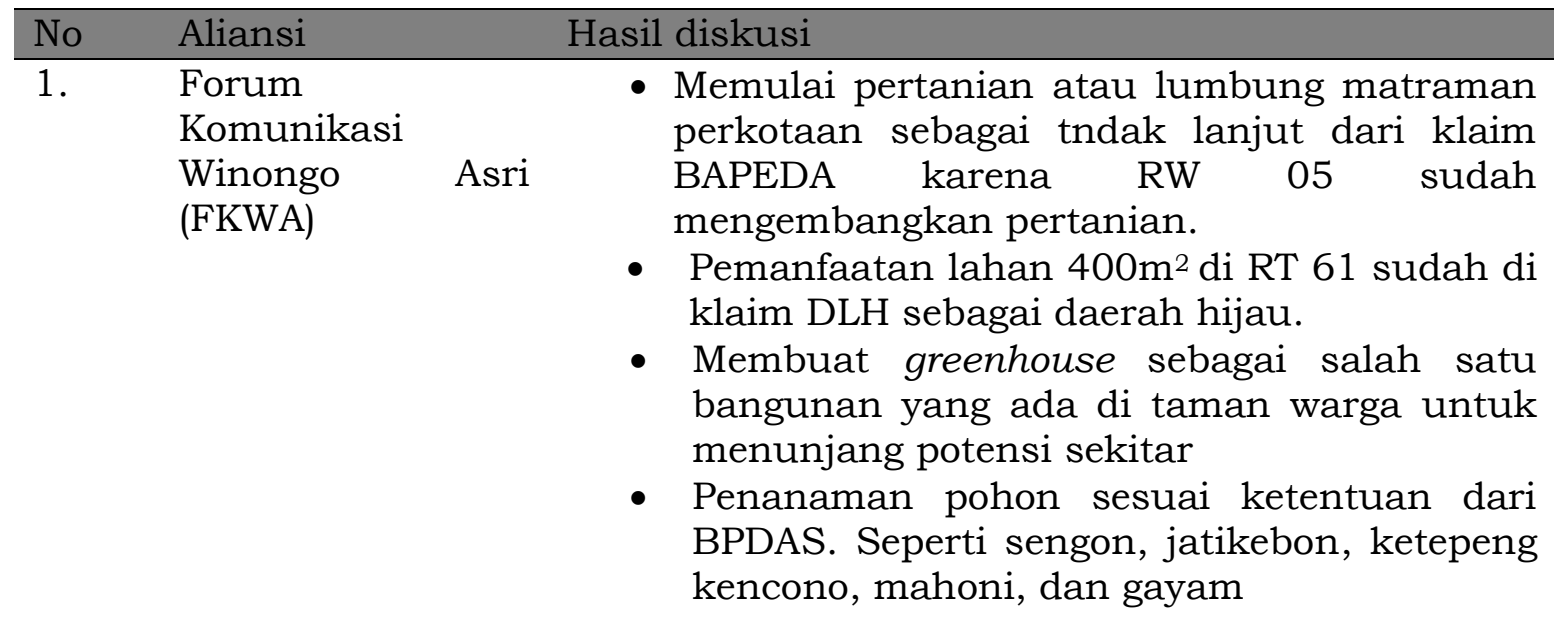

\begin{tabular}{ll}
\hline Warga & - Kebutuhan ruang interaksi secara edukasi, \\
& sosial dan ekonomi \\
& Edukasi tentang tata cara merawat \\
& tumbuhan dan hidroponik \\
\hline (Wahana & Rekomendasi desain Taman Warga meliputi \\
Lingkungan Hidup & potensi dan kebutuhan warga secara \\
Indonesia) WALHI & sosial(tempat berkumpul), edukasi(rumah \\
& magot dan green house) dan ekonomi (lapak \\
& pasar) Kangang \\
& Tanaman yang akan ditanami: Ketepeng \\
& kencono, matoa, kelapa gading
\end{tabular}

Desain Ruang Terbuka Hijau Jenis Taman Warga di dengan Pendekatan "Green Architecture" di Bantaran Sungai Winongo 


\section{PEMBAHASAN HASIL RANCANGAN}

Konsep yang di gunakan untuk merancang kawasan RTH yaitu "Green Architecture" berlandaskan peraturan kementrian PU Ruang Terbuka Hijau (RTH) berdasarkan luas site, jenis RTH yang di gunakan adalah katagori "Taman Warga". Serta memenuhi fungsi RTH secara sosial (tempat interaksi), budaya (bangunan mempresentasikan daerah site dengan nuansa jawa), Ekonomi (kegiatan jual beli). Elemen Konsep "Green Architecture" yang di terapkan yaitu :

\section{Merespon keadaan site}

Kebutuhan fungsi bangunan mengacu pada kebutuhan dan potensi yang sudah di miliki warga. Seperti klaim kampung sayur di RW 05 (tempat site RTH berada) oleh BAPEDA karena sektor pertanian nya maju maka di rencanakanlah lapak sayur yang akan dibangun pada sisi Timur laut (utara Green house) dengan ukuran 2x5. Sedangkan Green House akan di bangun pada sisi Tenggara, dan yang akan mendukung serta membudidayakan tanaman hidroponik. Rumah magot, dan pengelolaan sampah (komposting akan diletakkan pada sisi Barat Daya (Selatan ruang pertemuan) sebagai edukasi lingkungan serta mendukung kebutuhan Green House. Ruang pertemuan dengan luas $5 \times 5$ pada bagian pojok Barat Laut untuk ruang interaksi dan berkumpul. Serta adanya jogging track dan sitting area di RTH.

A) Conserving Energy (Hemat Energi)

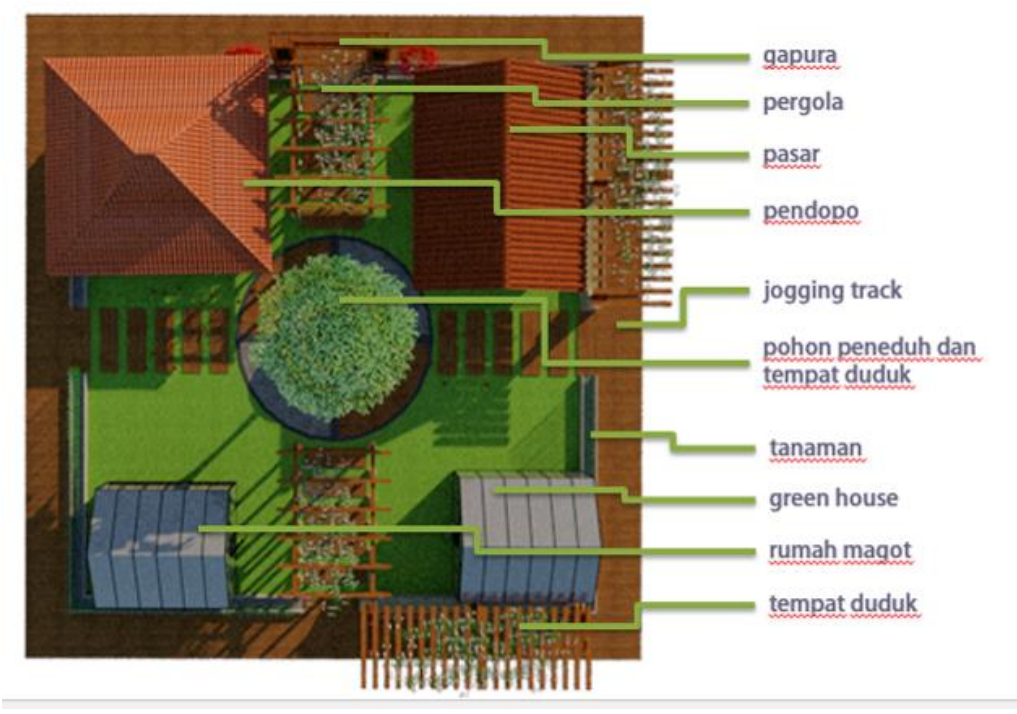

Gambar.5 Siteplan

Desain Ruang Terbuka Hijau Jenis Taman Warga di dengan Pendekatan "Green Architecture" di Bantaran Sungai Winongo 


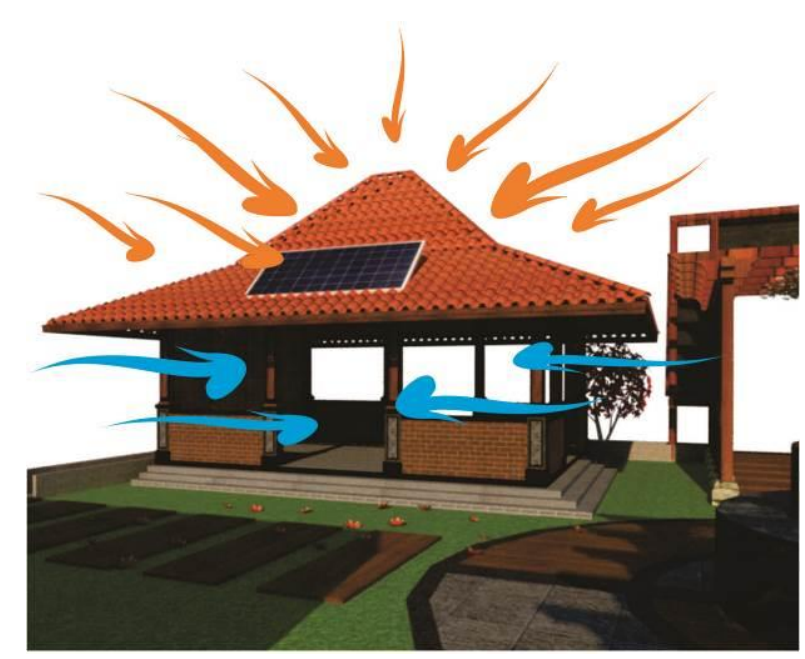

Gambar.6 detail Conserving Energy

Desain ruang interaksi di buat terbuka. Membuat pengguna merasa dekat satu sama lain dan saling mengetahui aktifitas di luar bangunan, selain itu penggunaan sumber cahaya matahari secara maksimal untuk penerangan, bukaan untuk penghawaan alami dan panel surya sebagai pengganti energy listrik.

B) Bahan bangunan alami

Material yang di gunakan di Taman Warga di buat alami dan tahan lama, selain untuk harmonisasi dengan alam atau peerapan dari konsep "Green Architecture" bahan yang tahan lama juga hemat.

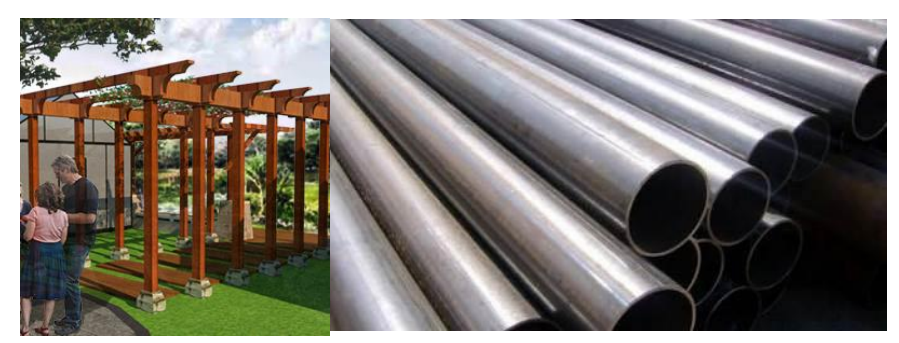

Gambar.7 Detail Material Pergola Dan Gapura

Penggunaan besi hollow untuk pergola dan gapura, selain ramah lingkungan bahan hollow lebih tahan lama dari pada bambu. Selain mempertahankan fungsi estetika, penggunaan hollow lebih hemat karena umur nya lebih panjang dari pada kayu ataupun bambu.

Desain Ruang Terbuka Hijau Jenis Taman Warga di dengan Pendekatan "Green Architecture" di Bantaran Sungai Winongo 


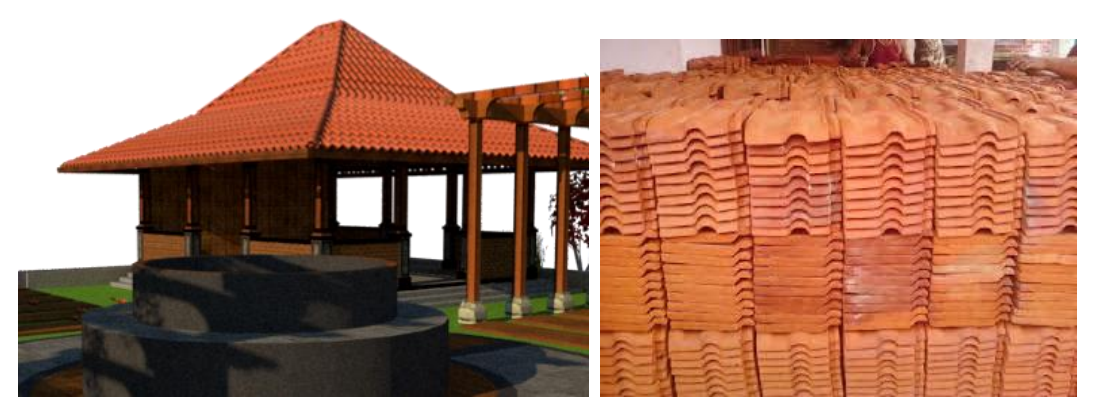

Gambar.8 Detail Genting Tanah Liat

Penggunaan genting tanah liat agar bagian dalam bangunan lebih sejuk serta tidak ada efek secara kimia yang dapat menggangu kesehatan para pengguna Taman Warga di Kricak. peguna.

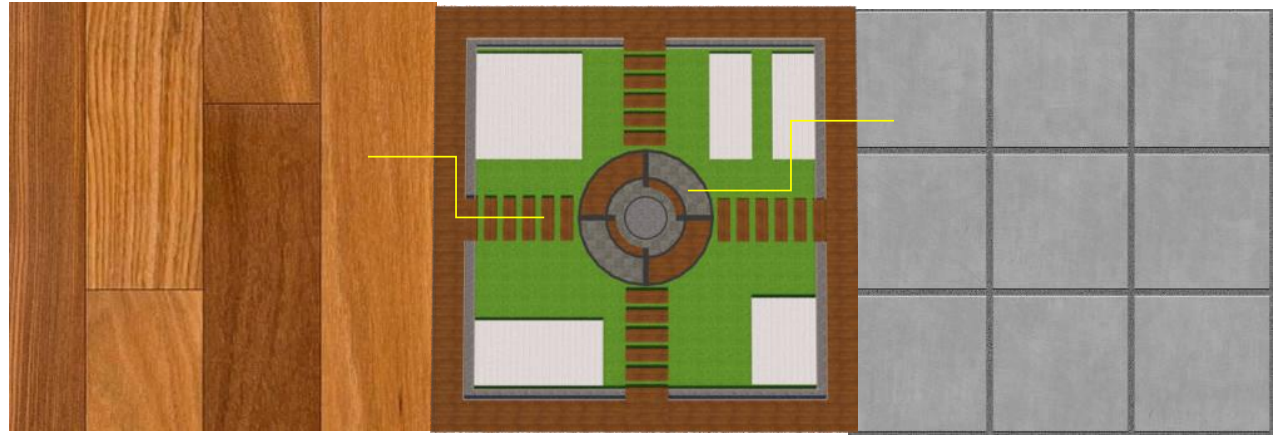

Gambar.9 Detail Lantai Beton Outdoor

Material yang di gunakan adalah paving beton polos. Agar warna lebih menyatu dengan alam, juga fungsinya sebagai tempat duduk dan memfasilitasi sirkulasi untuk berjalan pengunjung. Harga terjangkau dan tahan lama.

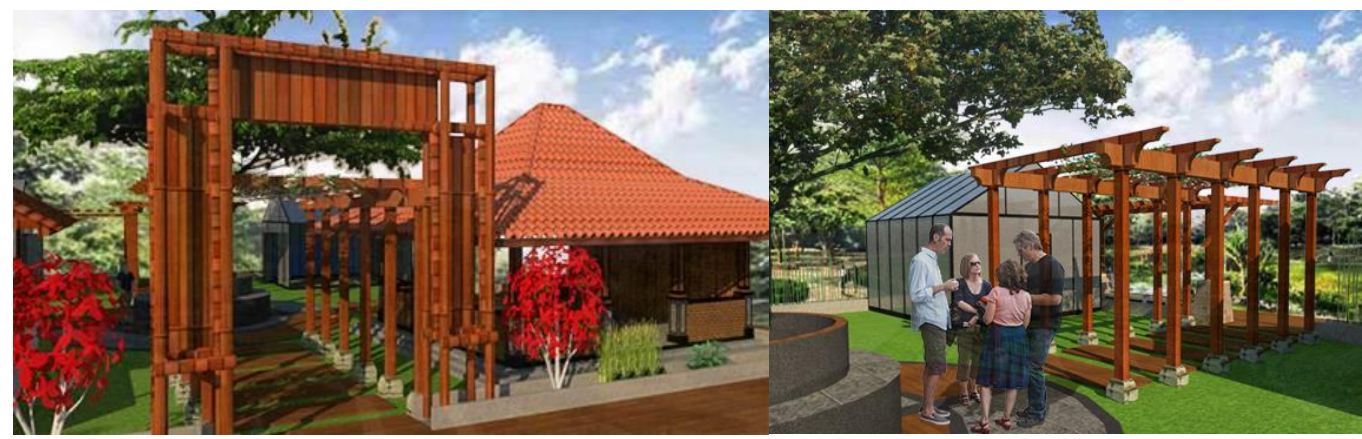

Gambar.10 Detail Prespektif

Desain Ruang Terbuka Hijau Jenis Taman Warga di dengan Pendekatan "Green Architecture" di Bantaran Sungai Winongo 


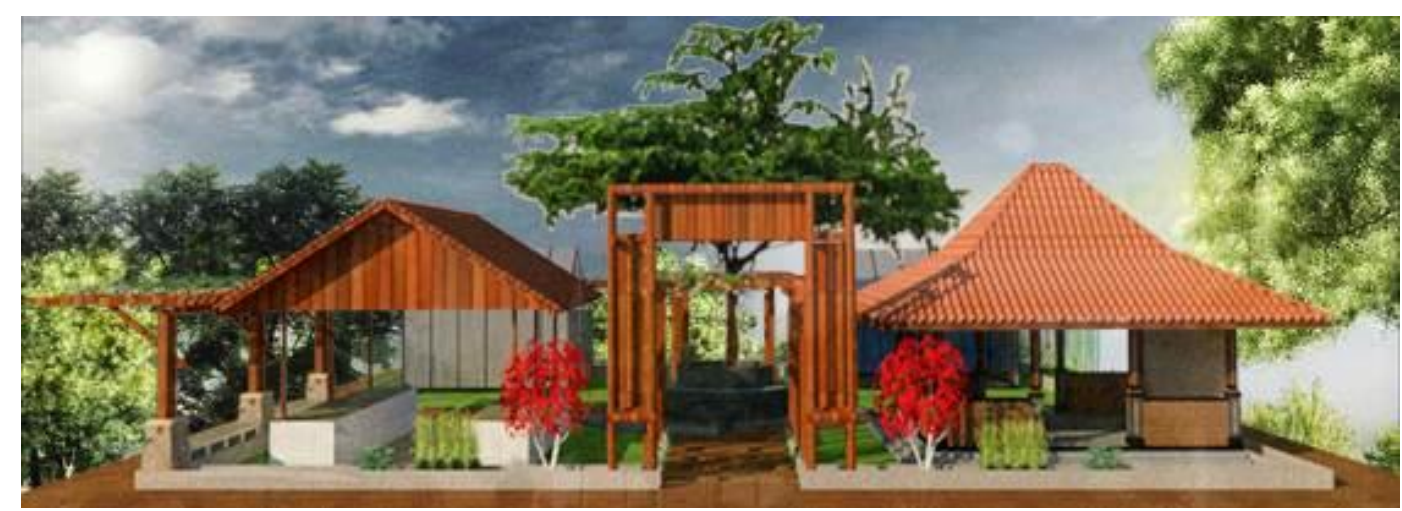

Gambar.11 Detail Tampak

\section{SIMPULAN}

Meluapnya Daerah Aliran Sungai (DAS) sungai Winongo yang diperparah dengan banyaknya pemukiman penduduk yang dibangun di bantaran sungai dan adanya Tempat Pembuangan Akhir (TPA), Menyebabkan fungsi tata guna lahan berubah dan berdampak negatif pada pada masyarakat di kawasan tersebut. Dengan inisiatif warga bersama Forum Komunikasi Winongo Asri (FKWA) bekerja sama dengan Wahana Lingkungan Hidup Indonesia (WALHI), untuk menutup TPA tersebut selain agar bantaran sungai tidak penuh dengan sampah dan banjir, bantaran sungai bisa menjadi area hijau.

Sehingga penggunaaan konsep “Green Architecture” yang berusaha meminimalkan pengaruh buruk terhadap lingkungan alam maupun manusia yaitu dengan cara Merespon potensi dan kebutuhan site maupun masyarakat sekitar, Hemat energy dengan cara membuat bukaan yang mampu meminimalisir kebutuhan cahaya dan udara buatan secara berlebihan serta menggunakan material alami serta meminimalisir energy yang di keluarkan dalam proses. Sedangkan landaskan peraturan kementrian PU yaitu, berdasarkan luas site, jenis RTH yang di gunakan adalah katagori "Taman Warga". Serta memenuhi fungsi RTH secara sosial (adanya tempat interaksi), budaya (bangunan mempresentasikan daerah site dengan nuansa jawa), Ekonomi (adanya lapak sayur untuk kegiatan jual beli).

\section{DAFTAR RUJUKAN}

Direktorat Jendral penataan ruang. 2008 Nomor 06/PRT/M/2008 tentang Pedoman penyediaan dan pemanfaat Ruang Terbuka Hijau (RTH)di kawasan perkotaan. Departemen Pekerjaan Umum (PU). 2008. Jakarta Selatan

Direktorat Jendral Penataan Ruang Departemen Pekerjaan Umum. 2007. Undang-undang No 26 tahun 2007 Tentang Penataan Ruang. Jakarta (ID): Direktorat Jendral Penataan Ruang Menteri Pekerjaan Umum.

Desain Ruang Terbuka Hijau Jenis Taman Warga di dengan Pendekatan "Green Architecture" di Bantaran Sungai Winongo 
Direktorat Jendral Penataan Ruang Departemen Pekerjaan Umum. 2008. Peraturan Menteri pekerjaan Umum Nomor: 05/PRT/M/2008 Tentang Pedoman Penyediaan dan Pemanfaatan Ruang Terbuka Hijau di Kawasan Perkotaan. Jakarta (ID): Direktorat Jendral Penataan Ruang Menteri Pekerjaan Umum.

Santoso, 2012. Pola Pemanfaatan Ruang Terbuka Hijau (RTH) pada kawasan perkampungan Plemburan Tegal, Ngaglik Sleman. Jurusan Teknik Sipil dan Perencanaan FT UNY.

Pra, 2018. Luas RTH jogja jauh dari target.Artikel Jawa Pos. (online), https://radarjogja.jawapos.com/2018/03/18/luas-rth-kota-jogja-jauhdari-target/, di akses 23 November 2019.

Dwita Hadi Rahmi, 2015. Arsitektur hijau. (online) http://arsitekturdanlingkungan.wg.ugm.ac.id/2015/08/27/arsitekturhijau/, di akses 23 November 2019.

Ratnasari, Amalia.2015. Yogyakarta Green City Planning based on Land Use and Adequacy of Green Open Space. BIRO PENERBIT PLANOLOGI UNDIP.

Desain Ruang Terbuka Hijau Jenis Taman Warga di dengan Pendekatan "Green Architecture" di Bantaran Sungai Winongo 